\title{
Adição de ácido cítrico potencializa a ação de ácidos húmicos e altera o perfil protéico da membrana plasmática em raízes de milho
}

\author{
Citric acid addition improve humic acids action and change proteins profile from plasma \\ membrane of maize roots
}

\author{
Janaína Aparecida Hottz Rima ${ }^{\mathrm{I}}$ Silvia Aparecida Martim ${ }^{\mathrm{II}}$ Leonardo Barros Dobbss ${ }^{\mathrm{I}}$ \\ Joseph Albert Medeiros Evaristo ${ }^{\text {III }}$ Claudio Andrés Retamal ${ }^{\text {IV }}$ Arnoldo Rocha Façanha $^{\text {IV }}$ \\ Luciano Pasqualoto Canellas ${ }^{\mathrm{V}}$
}

\section{RESUMO}

A promoção do crescimento vegetal pelos ácidos húmicos tem sido atribuída a ações similares a hormônios, devido à promoção do desenvolvimento e proliferação das raízes, resultando numa absorção mais eficiente de água e nutrientes. $O$ objetivo deste trabalho foi analisar as mudanças na arquitetura radicular em plântulas de milho e no perfil de proteínas da membrana plasmática $(M P)$ promovidas pelo tratamento com ácidos húmicos (AH) isolados de vermicomposto (20mg C $\mathrm{L}^{-1}$ ). O efeito da adição de ácido cítrico (AC), importante ácido orgânico presente nos exudados radiculares, sobre a bioatividade destes AH também foi investigada. Foram analisados o comprimento da raiz principal, o número de sítios de mitose, o número e comprimento de raízes laterais e a área radicular total. Para a análise do perfil protéico, vesículas da MP de células de raízes foram obtidas por fracionamento celular e as proteinas analisadas por eletroforese uni $(1 D)$ e bidimensional $(2 D)$. Observou-se que a adição de AC (0,005mM) aos $A H$ estimularam a promoção do crescimento das raízes laterais (126\%), da área radicular (58\%) e do número de raízes laterais (55\%) em relação às plantas controle. A atividade da bomba de $\mathrm{H}^{+}$da membrana plasmática, analisada como marcador bioquímico de indução do mecanismo do crescimento ácido, também foi significativamente estimulada (374\%) pela solução húmica suplementada com AC. O perfil protéico da MP revelou uma supressão da expressão das proteínas nesta membrana, induzida pelo tratamento com AH e, na presença de AC, esse efeito foi ainda mais evidente. Os resultados obtidos corroboram o mecanismo proposto para a bioatividade de AH no qual a ação de ácidos orgânicos exudados pelas plantas, tais como o AC, promove o rompimento da associação supramolecular dessas substâncias, tornando as moléculas bioativas presentes nos agregados húmicos mais acessiveis aos receptores celulares das raizes.

Palavras-chave: substâncias húmicas, $H^{+}$-ATPases, análise proteômica, proteínas de membrana, partição de fase.

\section{ABSTRACT}

The plant growth stimulation by humic acids (HA) has been attributed to a hormone-like effect as promoting the root development and proliferation, resulting in a more efficient water and nutrient absorption. This research aims to investigate how the humic acids isolated from vermicompost $\left(20 \mathrm{mg} \mathrm{L}^{-1}\right)$ can modify the root architecture and the plasma membrane $(P M)$ protein patterns in maize roots. It was also analyzed the effect of the citric acid (CA), an organic acid present in root exudates. The changes induced in the corn root system were estimated by measuring the taproot length, the amount of root mitotic sites and lateral roots, and the total root area. Plasma membrane vesicles were purified by cell fractionation and the protein patterns were analyzed by uni (1D) and bidimensional (2D) electrophoresis. The results show that the HA in solution with $C A(0.005 \mathrm{mM})$ increases the lateral root growth promotion $(126 \%)$, the root area $(58 \%)$, and the number of lateral roots $(55 \%)$. The activity of the plasma membrane $\mathrm{H}^{+}$pump, analyzed as a marker of the induction of the acid growth mechanism, was also enhanced (374\%) by the humic solution supplemented

'Programa de Pós-graduação em Produção Vegetal, Universidade Estadual do Norte Fluminense (UENF), Campos dos Goytacazes, RJ, Brasil.

IIDepartamento de Ciências Fisiológicas, Universidade Federal Rural do Rio de Janeiro (UFRRJ), Seropédica, RJ, Brasil.

"IIPrograma de Pós-graduação em Biociências, UENF, Campos dos Goytacazes, RJ, Brasil.

${ }^{\mathrm{IV}}$ Laboratório de Biologia Celular e Tecidual, UENF, Campos dos Goytacazes, RJ, Brasil.

vNúcleo de Desenvolvimento de Insumos Biológicos para Agricultura, UENF, n 2000, 28013-600, Campos dos Goytacazes, RJ, Brasil. E-mail: canellas@uenf.br. Autor para correspondência. 
with CA. Expression of several plasma membrane proteins was inhibited when plants were treated with HA and this effect was more pronounced upon CA supplementation. The obtained results corroborate the proposed mechanism for the HA bioactivity, by which under the action of root-exuded organic acids, such as CA, a disruption of the HA macrostructure is promoted releasing bioactive molecules presented in the humic aggregates, which becomes more accessible to the root cell receptors.

Key words: humic substances, $H^{+}$-ATPases, proteomic analyzes, membrane proteins, phase partitioning.

\section{INTRODUÇÃO}

Os ácidos húmicos (AH) estimulam o desenvolvimento e o metabolismo das plantas, atuando principalmente sobre o sistema radicular (NARDI et al., 2002). $\mathrm{A} \mathrm{H}^{+}$-ATPase funciona como uma bomba de prótons $\left(\mathrm{H}^{+}\right)$acionada pela hidrólise de ATP, sendo responsável pelo transporte primário de $\mathrm{H}^{+}$do interior da célula para o apoplasma e, consequentemente, pela formação do gradiente de $\mathrm{H}^{+}$gerado através da membrana plasmática (MORSOMME \& BOUTRY, 2000). Esse gradiente de $\mathrm{H}^{+}$energiza o transporte secundário de íons e outros metabólitos contra um gradiente de concentração. Um dos fenômenos que têm sido mais relacionados com a bioatividade das substâncias húmicas corresponde à acidificação da parede celular, causada pela ativação da $\mathrm{H}^{+}$-ATPase de membrana plasmática (CANELLAS et al., 2006). Esse evento é tido como o evento inicial da expansão celular. Esse mecanismo é conhecido como teoria do crescimento ácido (RAYLE \& CLELAND, 1992) e está associado com a ação da auxina, um hormônio vegetal que ativa a H+-ATPase.

A proliferação das raízes secundárias e a ativação das bombas de prótons localizadas na membrana plasmática (MP) são fenômenos relacionados à bioatividade de AH (CANELLAS et al., 2002). Além das $\mathrm{H}^{+}$-ATPases de MP, os AH podem regular as bombas do vacúolo, sugerindo a existência de um mecanismo complexo de regulação do metabolismo energético celular análogo ao descrito para auxinas (ZANDONADI et al., 2007).

Apesar de apresentarem massa molecular aparente de até milhões de Daltons, os AH são tão ou mais eficientes que os fúlvicos na indução do crescimento radicular. AGUIAR et al. (2009) e CANELLAS et al. (2010), utilizando a cromatografia por exclusão de tamanho, verificaram que a dimensão molecular não é decisiva na bioatividade dos $\mathrm{AH}$. Biofragmentos provenientes de plantas e microrganismos podem ser preservados da degradação no interior do domínio hidrofóbico da supramolécula húmica (SPACCINI et al., 2000) e liberadas para o meio via ruptura dos agregados húmicos, desencadeada pela adição de ácidos orgânicos (PICCOLO, 2002). Foi observado previamente que a promoção da atividade das bombas de $\mathrm{H}^{+}$de MP varia a hidrofobicidade dos AH (CANELLAS et al., 2009). Além disso, o tratamento de plântulas com AH modificou o perfil de exsudação de ácidos orgânicos pelas raízes, aumentando a concentração destes em solução e a bioatividade dos AH (CANELLAS et al., 2008). A relação entre respostas das plantas e mudanças conformacionais de AH relacionada à ação de ácidos orgânicos, dentre outras possibilidades, abre uma nova perspectiva para geração de insumos biológicos mais eficientes.

O objetivo deste trabalho foi avaliar o efeito da adição de ácido cítrico (AC) à solução de AH sobre o desenvolvimento do sistema radicular de plântulas de milho, a atividade $\mathrm{H}^{+}$-ATPásica e o perfil proteico associados a MP.

\section{MATERIAL E MÉTODOS}

Os AH obtidos de vermicomposto foram isolados e purificados conforme descrito previamente em CANELLAS et al. (2002). Plântulas de milho (Zea mays L., var UENF 506/6) homogêneas foram selecionadas e transferidas para um meio mínimo contendo $\mathrm{CaCl}_{2} 2 \mathrm{mM}$ (Controle), meio mínimo acrescido de $\mathrm{AH}$ (20mg de $\mathrm{C} \mathrm{L}^{-1}$, previamente descrita como concentração ótima para a promoção do crescimento) isolado de vermicomposto (AH) e meio mínimo

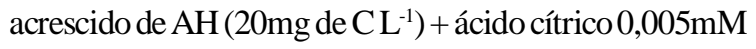
$(\mathrm{AH}+\mathrm{AC}) . \mathrm{O} \mathrm{pH}$ da solução foi ajustado para 5,5 com solução diluída de $\mathrm{NaOH}$ e/ou $\mathrm{HCl}$. Após quatro dias de tratamento, as plântulas foram coletadas para as análises. Amostras de raízes $(\mathrm{n}=10)$ foram digitalizadas e o comprimento radicular total e a área radicular de cada plântula foram estimadas pelo programa Delta-T $S c a n^{\mathrm{TM}}$. Os sítios de mitose no sistema radicular foram realizados após digestão com $\mathrm{KOH}(0,5 \%, \mathrm{~m} / \mathrm{v}, 20 \mathrm{mim}$, $75^{\circ} \mathrm{C}$ ) e revelados após coloração com hetatoxilina férrica pela adição de ácido lático, conforme descrito em CANELLAS et al. (2002). A atividade das bombas de prótons de MP foi determinada na fração microssomal, obtida de acordo com De MICHELIS E SPANSWICH (1986). A atividade de hidrólise de ATP sensível a vanadato, relacionada a $\mathrm{H}^{+}$-ATPase tipo $\mathrm{P}$ foi determinada colorimetricamente. A reação foi iniciada com a adição de ATPe paralisada pela adição de ácido tricloroacético e quantificada a $750 \mathrm{~nm}$. Em todos os experimentos, a atividade hidrolítica da $\mathrm{H}^{+}$-ATPase foi medida a $30^{\circ} \mathrm{C}$, com ou sem vanadato e a diferença à 
$\mathrm{H}^{+}$-ATPase de MP. A análise do perfil protéico na MP foi determinada em frações purificadas pelo procedimento de partição de fase, utilizando-se 6,2\% dos polímeros Dextran/PEG (Ephrikhine et al., 2004). A membrana ressuspendida $(1,0 \mathrm{~mL})$ foi adicionada a 4,0 $\mathrm{mL}$ de um sistema de duas fases polímero aquosa contendo a composição final de Dextran 500 6,2\% (p/ p), PEG $33506,2 \%$ (p/p), MOPS-KOH 25mM (pH 7,8), sacarose 250mM, KCl 10mM, EDTA0,1mM, DTT $1 \mathrm{mM}$. As fases finais superiores foram diluídas pelo menos duas vezes em meio contendo: PEG 3350 6,2\% (p/p), MOPS-KOH 25mM ( $\mathrm{pH} 7,8$ ), sacarose $250 \mathrm{mM}, \mathrm{KCl}$ $10 \mathrm{mM}$, EDTA 0,1mM, DTT 1mM. Os tubos foram agitados por inversão ( 40 vezes) sendo posteriormente submetidos à centrifugação de $1500 \mathrm{x}$ g por $5 \mathrm{~min}$. Por fim, a membrana plasmática foi isolada pela ultracentrifugação a 100000 x g por $60 \mathrm{~min}$. Todos os procedimentos foram realizados a $4^{\circ} \mathrm{C}$ e a concentração de proteínas da fração de vesículas foi determinada conforme a método clássico de Bradford, utilizando albumina sérica bovina (BSA) como padrão.

As determinações eletroforéticas por SDSPAGE foram realizadas em alíquotas de $50 \mu \mathrm{L}$ provenientes da partição de fase que foram submetidas a eletroforese em gel desnaturante (SDS-PAGE), conforme metodologia descrita por LAEMMLI (1970). As análises da mobilidade eletroforética e a quantificação relativa das bandas foram realizadas mediante varredura (scanner) do gel unidimensional, obtendo uma imagem em formato TIFF em um software comercial e logo se realizou o estudo densitométrico, que utilizou o programa computacional gel perfect (RETAMAL et al., 1999). A determinação da massa molecular relativa foi realizada relacionando a mobilidade das proteínas das amostras em estudo com aquelas de proteínas de massa molecular conhecida, utilizando o mesmo programa computacional (RETAMAL et al., 1999). As eletroforeses bidimensionais (2-D) seguiram o método elaborado por O'FARREL (1975), com algumas inovações feitas por GORG et al. (1980). Dentre elas, consta um gradiente de pH imobilizado, gerado através da polimerização de anfólitos químicos com a matriz de acrilamida para a focalização isoelétrica na primeira dimensão, no sistema de focalização IPGphor (GE). O extrato contendo as proteínas, $60 \mu \mathrm{g}$, foram diluídos em solução de focalização isoelétrica (IEF) (constituído de uréia 8M, CHAPS $2 \%$ m/v, tampão IPG (pH 3-10) 2\%, azul de bromofenol 1 $\mu \mathrm{l}$ ) e usados para re-hidratação das tiras de gel. A eletrofocalização procedeu-se em tiras de gel de $7 \mathrm{~cm}$, com gradiente de $\mathrm{pH}$ imobilizado de 3 a 10 (Amersham-Pharmacia) em aproximadamente $28.000 \mathrm{Vh}$. A segunda dimensão foi realizada usando-se um sistema vertical para eletroforese (BIORAD) sob voltagem constante de $120 \mathrm{~V}$.

Para o estudo de morfologia e atividade das bombas de $\mathrm{H}^{+}$de MP, foi utilizado o delineamento experimental inteiramente casualizado, com 10 repetições para cada tratamento. Foi realizada a análise da variância e as médias foram comparadas pelo teste DMS P $<0,05$ pelo programa SISVAR da Universidade Federal de Lavras (UFLA). Para análise do perfil eletroforético uni e bi-dimensional, também foi utilizado o delineamento experimental inteiramente casualizado, porém com duas repetições para cada tratamento, cada vaso com aproximadamente 300 plântulas.

\section{RESULTADOS E DISCUSSÃO}

As plântulas de milho tratadas com $\mathrm{AH}$ e na solução suplementada com ácido cítrico (AC) induziram mudanças significativas no padrão de enraizamento em comparação com as plantas controle (Figura 1). O comprimento do eixo principal (CEP) das plântulas tratadas com $\mathrm{AH}$ e $\mathrm{AH}+\mathrm{AC}$ apresentaram uma redução de aproximadamente $40 \%$ e $28 \%$, respectivamente, em relação ao controle (Figura 1A), enquanto o número de raízes laterais emergidas aumentou $37 \%$ em relação ao controle no tratamento com $\mathrm{AH}$ e $55 \%$ com a solução de AH suplementada com AC (Figura 1B). O encurtamento do eixo principal e a concomitante indução da emissão de raízes laterais são características bem documentadas em plantas tratadas com concentrações elevadas de auxina exógena (e.g., CANELLAS et al., 2002; ZANDONADI et al., 2007), o que sugere a presença do hormônio ou uma ação do tipo hormonal do $\mathrm{AH}$ isolado de vermicomposto. As plântulas tratadas com $\mathrm{AH}$ aumentaram a área de seu sistema radicular em $45 \%$, enquanto que, na suplementação da solução de AH com ácido cítrico, esse aumento foi de $58 \%$ em relação às plântulas controle (Figura 1C). A maior indução do comprimento das raízes laterais obtida com o $\mathrm{AH}$ suplementado com AC pode indicar uma maior disponibilização das moléculas com atividades auxínicas presentes nas $\mathrm{AH}$ (Figura 1D). O número maior de raízes fisiologicamente ativas concomitantemente com a maior área superficial radicular promove aumento do volume que pode ser explorado pelas raízes representando uma vantagem significativa proporcionada pelo tratamento das plântulas com as substâncias húmicas. O aumento da emergência de raízes laterais pode ter efeitos significativos sobre a produção, uma vez que colabora para a maior adaptação das plantas ao ambiente do solo sob várias condições adversas, bem como para o aumento da absorção de nutrientes (NIBAU et al., 2008). 


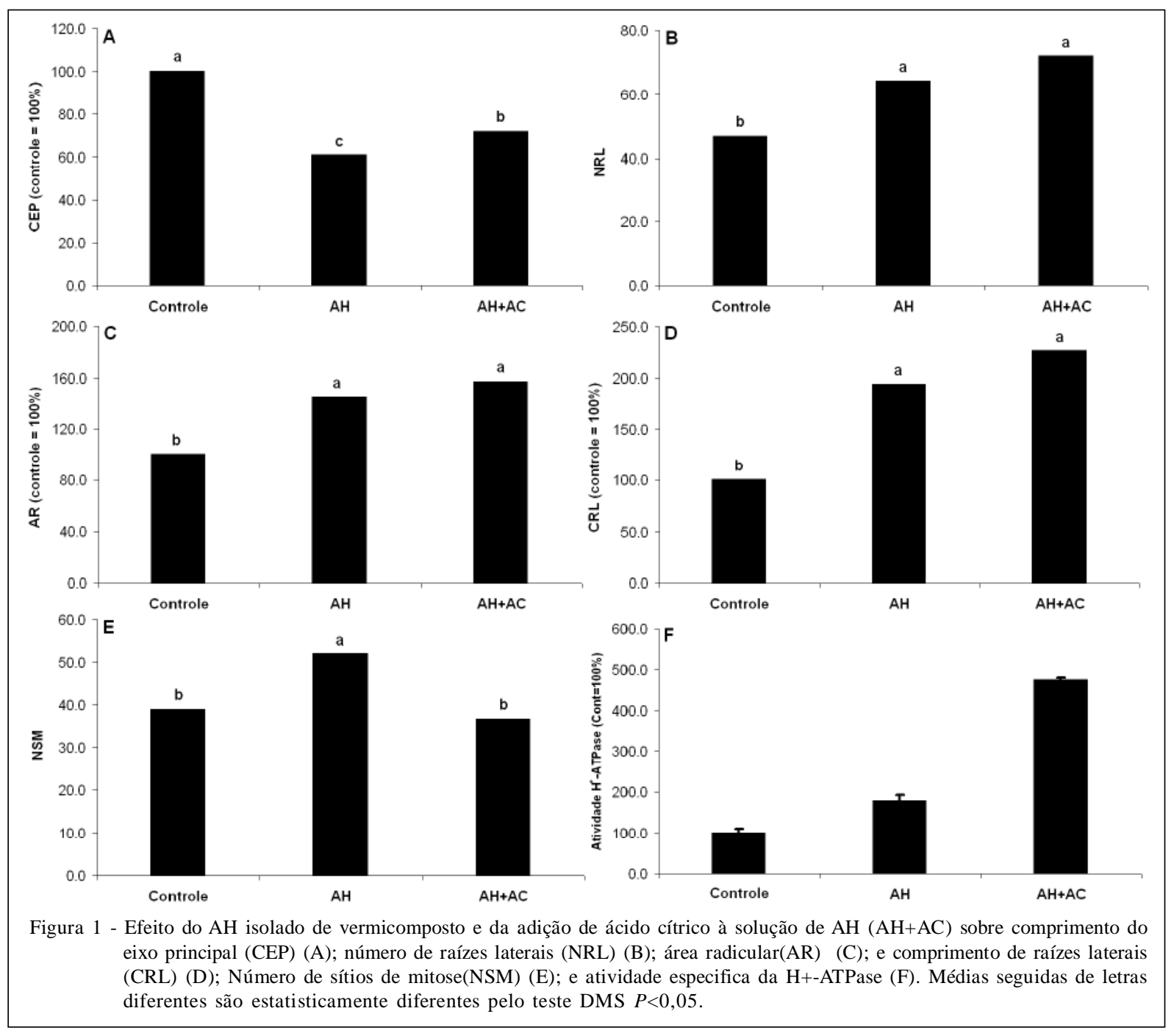

Mudanças morfofisiológicas no sistema radicular promovidas pelas substâncias húmicas foram observadas já há bastante tempo. Segundo PARRY \& ESTELLE (2006), o sinal primário que dispara a iniciação da raiz lateral é promovido pela auxina que induz a iniciação da raiz lateral pelo transporte polar basípeto, i.e., das folhas jovens até a ponta da raiz por intermédio do cilindro vascular (pelo periciclo ou xilema diferenciado). Curiosamente, observa-se, na figura 1E, que $\mathrm{o} \mathrm{AH}$ induziu um aumento significativo no número de sítios de mitose, enquanto o tratamento com $\mathrm{AH}+\mathrm{AC}$ se manteve igual ao controle. Uma vez que foi observado uma maior indução em número e comprimento das raízes laterais no tratamento $\mathrm{AH}+\mathrm{AC}$ (Figura 1B e 1D), os dados da figura 1 sugerem que o $\mathrm{AC}$ atua sobre os $\mathrm{AH}$, capacitando-os a promover uma resposta mais rápida sobre a elongação das raízes laterais recém induzidas, possibilitando que os primórdios radiculares possam se tornar raízes mais rapidamente. As MP isoladas das raízes de plântulas de milho tratadas por sete dias com $\mathrm{AH}$ e $\mathrm{AH}+\mathrm{AC}$ apresentaram um estímulo da atividade ATPásica (Figura 1F). O tratamento com AH promoveu um incremento de $77 \%$ na hidrólise de ATP sensível ao vanadato em relação ao controle, enquanto a estimulação dos AH na presença de AC passou a ser de $374 \%$. A ativação da $\mathrm{H}^{+}$-ATPase de MP de células radiculares induzida por $\mathrm{AH}$ tem sido relacionada com a indução do mecanismo de crescimento ácido responsável pela elongação da raiz (CANELLAS et. al., 2002; ZANDONADI et al., 2007; AGUIAR et. al., 2009; CANELLAS et. al, 2010). O gradiente eletroquímico gerado pelas bombas de prótons energiza os transportadores secundários de íons, favorecendo a absorção e a nutrição das plantas. Além disso, o abaixamento do $\mathrm{pH}$ no apoplasto promove condições 
apropriadas para a atividade das expansinas, enzimas responsáveis pela hidrólise das ligações entre os polímeros que compõe a parede celular, favorecendo a expansão da célula (RAYLE \& CLELAND, 1992). No presente trabalho, foi utilizada a ativação das bombas de prótons como marcador bioquímico da bioatividade das substâncias húmicas, como previamente proposto (CANELLAS et al., 2002).

OHNO et al. (2004) relataram que há uma relação direta entre a atividade da $\mathrm{H}^{+}$-ATPase e a exsudação de citrato para manutenção do equilíbrio hidrogeniônico. A adição de $\mathrm{AC}$ à solução de $\mathrm{AH}$ promoveu modificações na distribuição de massa/ tamanho molecular das substâncias húmicas, rompendo o arranjamento supramolecular em solução (PICCOLO, 2002). CANELLAS et al. (2008) observaram que os AH induziram a maior exsudação radicular de ácidos orgânicos. Os dados da figura 1E sugerem que moléculas orgânicas com ação similar à de fitormônios e protegidas nos domínios hidrofóbicos das substâncias húmicas podem ser liberadas pela adição de $\mathrm{AC}$ e acessar mais facilmente receptores celulares, desencadeando a amplificação de respostas bioquímicas tais como as observadas na atividade hidrolítica das bombas de prótons da MP. Tal modelo prevê que não só a $\mathrm{H}^{+}$-ATPase, mas várias outras proteínas da MP, entre outras, proteínas transportadoras, canais e receptores, devam ser direta ou indiretamente influenciados pelas moléculas bioativas presentes nos $\mathrm{AH}$.

No intuito de verificar tais alterações no perfil protéico da MP nas células de raízes tratadas com $\mathrm{AH}$ suplementados ou não com $\mathrm{AC}$, foram realizadas análises eletroforéticas uni (1D) e bidimensionais (2D). A análise densitometrica dos géis SDS-PAGE 1D (Figura 2A) permitiu observar indução de bandas indicativas de proteínas com massa aproximada de 178 e $147 \mathrm{kDa}$, tanto pelo tratamento com $\mathrm{AH}$ quanto com $\mathrm{AH}$ suplementados com $\mathrm{AC}$, as quais não foram encontradas nas plantas controle. Essas bandas representaram $10 \%$ a $14 \%$ do total de proteínas de MP nas plantas tratadas com AH e com AH+AC. Por outro lado, proteínas de aproximadamente $136 \mathrm{kDa}$ apareceram somente nas planta controle, enquanto proteínas de 31 e $101 \mathrm{kDa}$ foram expressas somente em plantas tratadas com AH+AC. Proteínas de 38 a 39kDa estão presentes em todos os tratamentos e no controle, porém aparecem em maior intensidade para o tratamento AH+AC. Proteínas de 25, 32 e 94kDa foram suprimidas pelo tratamento do $\mathrm{AH}+\mathrm{AC}$, aparecendo em proporção igual tanto no controle quanto no tratamento com $\mathrm{AH}$, enquanto as de $21,18 \mathrm{e}$ $15 \mathrm{kDa}$ foram totalmente inibidas quando tratadas com $\mathrm{AHe} \mathrm{AH}+\mathrm{AC}$.
Bandas com Rf em torno de 0,21 cuja massa é de aproximadamente $66 \mathrm{kDa}$, aparecem mais fortes em relação às outras bandas, provavelmente por causa da adição de BSA durante o processo de extração. Observou-se que sete bandas do gel foram suprimidas e que duas bandas foram expressas com $\mathrm{AH}$, porém inibidas quando tratadas com $\mathrm{AH}+\mathrm{AC}$. No total, 11 bandas do gel foram totalmente inibidas pelo tratamento com AH+AC, e duas aparecem somente nesta condição (Figura 2A).

A figura $2 \mathrm{~B}$ apresenta os géis $2 \mathrm{D}$ das proteínas de MP das células de raízes de milho, nos quais foram revelados 22,15 e 8 spots nas plantas controle e nas tratadas com $\mathrm{AH}$ e $\mathrm{AH}+\mathrm{AC}$, respectivamente. $\mathrm{O}$ tratamento $\mathrm{AH}+\mathrm{AC}$ inibiu a expressão das proteínas em $63 \%$ em relação ao controle e no AH essa inibição foi de aproximadamente $30 \%$. As proteínas com expressões diferenciais aqui indicadas ainda precisam ser identificadas em futuros estudos funcionais e análises proteômicas. Assim, corroborando os presentes dados, CARLETTI et al. (2008) relataram que plântulas de milho tratadas com substâncias húmicas apresentaram inibição de várias proteínas envolvidas em diferentes rotas metabólicas. Esses autores constataram que além da indução das $\mathrm{H}^{+}$ATPase pelas substâncias húmicas outras proteínas envolvidas no transporte celular, tais como as anexinas, tiveram sua expressão aumentada. De forma contrária, algumas proteínas envolvidas na sinalização celular, como, por exemplo, as cinases dependentes de $\mathrm{Ca}^{+2}$, as proteínas 14-3-3 e a lipoxigenase foram inibidas.

O presente estudo apresenta as primeiras evidências de significativas alterações na bioatividade dos $\mathrm{AH}$ induzidos pela ação do AC, as quais afetam drasticamente o perfil proteico da MP, indicando uma ativação diferencial de receptores e transdutores de energia e sinais envolvidos com a modulação morfofisiológica do sistema radicular. A identificação desses sistemas proteicos e a caracterização das rotas metabólicas e de sinalização em que atuam constituem passo importante para o entendimento dos efeitos fisiológicos promovidos pelas substâncias húmicas, constituindo importantes alvos para futuras pesquisas.

\section{CONCLUSÃO}

Os AH modificaram a morfologia do sistema radicular e promoveram aumento no número de raízes fisiologicamente ativas e na área radicular. A adição de pequenas concentrações de AC potencializou a capacidade de estimulação dos $\mathrm{AH}$, principalmente sobre o crescimento das raízes laterais por meio de um mecanismo que depende da ativação das bombas de prótons da MP. 


\section{A}

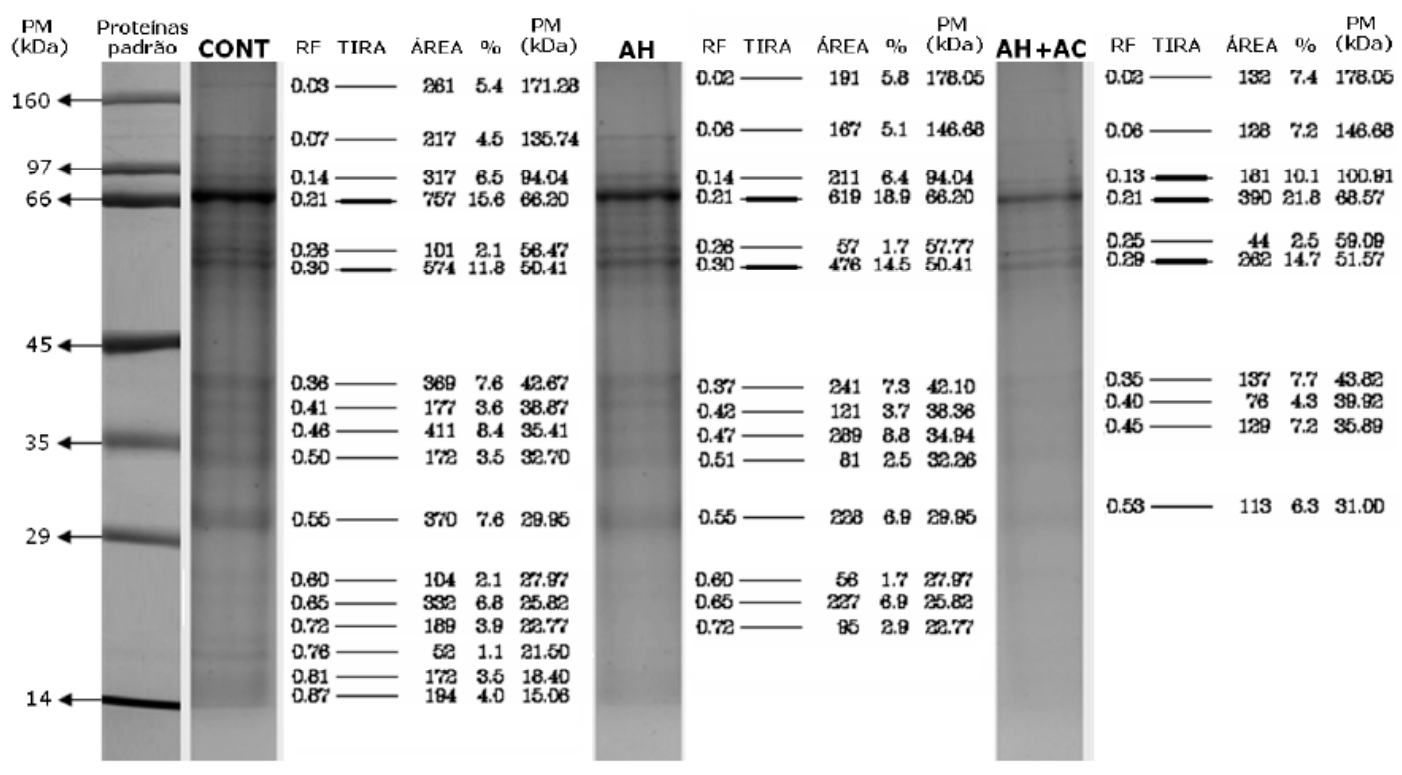

B
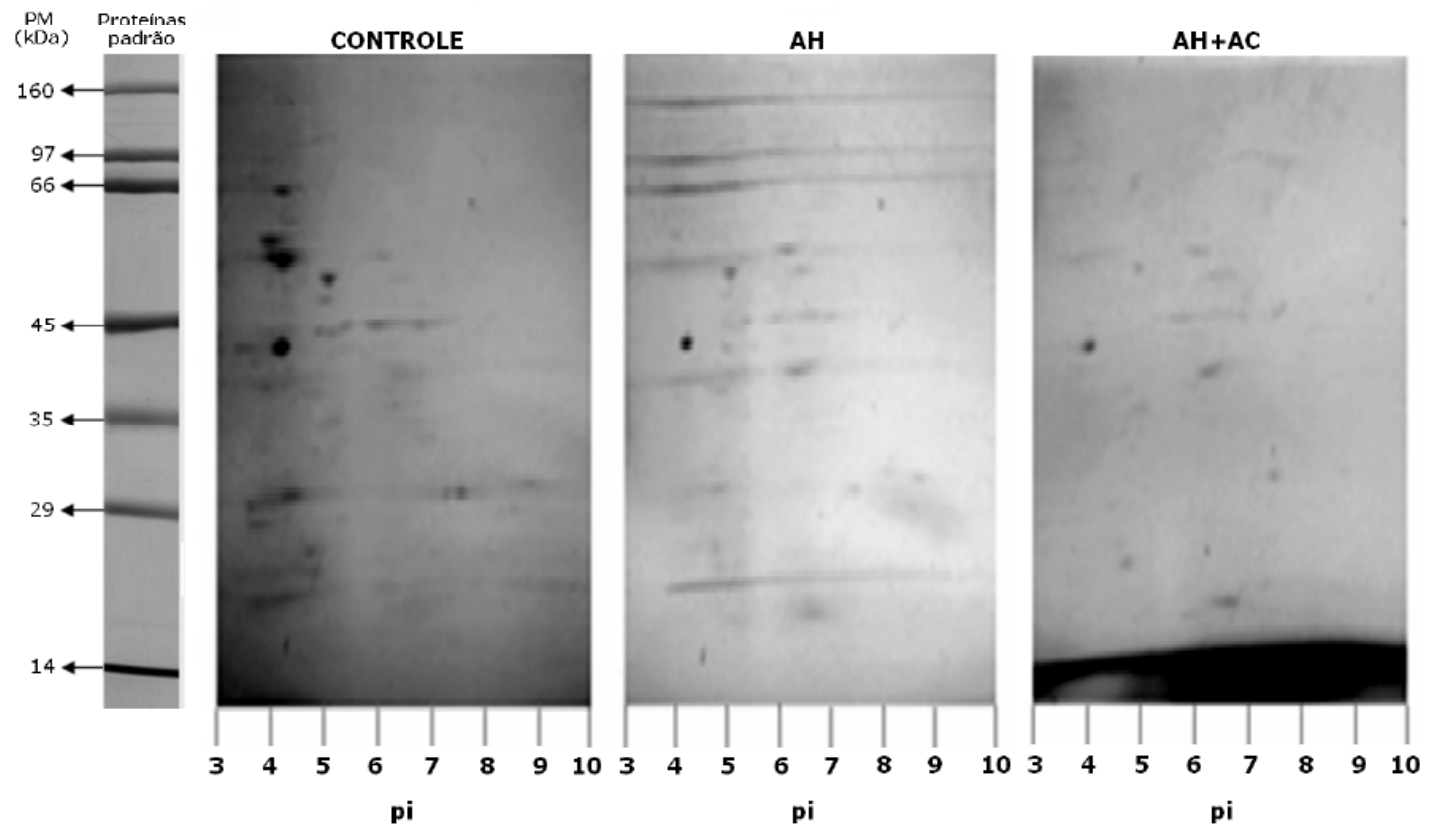

Figura 2 - A: Gel SDS-PAGE 12\% unidimensional (1D) das proteínas isoladas da membrana plasmática de raízes de milho tratadas ou não (controle) com ácidos húmicos $(\mathrm{AH})$ e solução de ácidos húmicos $\left(20 \mathrm{mg} \mathrm{C} \mathrm{L}^{-1}\right)$, suplementada com ácido cítrico na concentração de $0,005 \mathrm{mM}$ (AH+ AC). B: Gel SDS-PAGE 12\% bidimensional (2D).

O perfil de expressão proteica da MP foi sensivelmente alterado pelo tratamento dos $\mathrm{AH}$ com o ácido cítrico, indicando que diferentes alvos moleculares são ativados ou reprimidos quando a supraestrutura molecular das substâncias húmicas é modificada. A confirmação e o melhor entendimento da ação dos ácidos orgânicos sobre a bioatividade dos
AH abre novas perspectivas para a produção de substâncias húmicas mais eficientes na promoção do crescimento vegetal.

\section{REFERÊNCIAS}

AGUIAR N.O. et al. Distribuição de massa molecular de ácidos húmicos e promoção do crescimento radicular. Revista 
Brasileira de Ciência do Solo, v.33, p.1613-1623, 2009. Disponível em: <http://www.scielo.br/scielo.php>. Acesso em: 20 jan. 2010. doi: 10.1590/S0100-06832009000600010.

CANELLAS, L.P. et al. Efeitos fisiológicos de substâncias húmicas - o estímulo às $\mathrm{H}^{+}$-ATPases. In: FERNANDES, M.S. Nutrição mineral de plantas. Viçosa: SBCS, 2006. Cap.2, p.175-200.

CANELLAS, L.P. et al. Chemical composition and bioactivity properties of size-fractions separated from a vermicompost humic acid. Chemosphere, v.78 p. 457-466, 2010. Disponível em: 〈http://www.sciencedirect.com/science>. Acesso em: 20 jan. 2010. doi: 10.1016/j. chemosphere.2009.10.018.

CANELLAS, L.P. et al. Humic acids isolated from earthworm compost enhance root elongation, lateral root emergence, and plasma membrane $\mathrm{H}^{+}$-ATPase activity in maize roots. Plant Physiology, v.130 p.1951-1957, 2002. Disponível em: <http:/ /www.plantphysiol.org>. Acesso em: 05 abr. 2010. doi: 10.1104/ pp.007088.

CANELLAS, L.P. et al. Relationships between chemical characteristics and root growth promotion of humic acids isolated from brazilian oxisols. Soil Science, v.174: 611-620, 2009. Disponível em:<http://www.plantphysiol.org>. Acesso em: 18 nov. 2009. doi: 10.1097/SS.0b013e3181bf1e03.

CARLETTI, P. et al. Protein expression changes in maize roots in response to humic substances. Journal of Chemical Ecology, v.34 p.804-818, 2008. Disponível em: <http:// www.springerlink.com>. Acesso em: 02 fev. 2010. doi: 10.1007/ s10886-008-9477-4.

DE MICHELIS, M.I.; SPANSWICK, R.M. $\mathrm{H}^{+}$-pumping dive by vanadate sensitive ATPase in membrane vesicles from corns roots. Plant Physiology, v.81 p.542-547, 1986. Disponível em: <http://www.plantphysiol.org>. Acesso em: 18 mar. 2009. doi: 0032-0889/86/81 /0542/06.

GORG, A. et al. Gel gradient electrophoresis, isoelectric-focusing and two-dimensional techniques. In: Horizontal, Ultrathin Polyacrylamide Layers. Journal of Biochemical and Biophysical Methods, p.273-284, 1980. Disponível em: <http://www.sciencedirect.com/science>. Acesso em: 20 jan. 2010. doi:10.1016/0165-022x(80)90008-1.

LAEMMLI, U.K. Cleavage of structural proteins during assembly of head of bacteriophage-t4. Nature, v.227, p.680685, 1970. Disponível em: 〈http://www.nature.com>. Acesso em: 15 jan. 2010. doi: 10.1038/227680a0.

MORSOMME, P.; BOUTRY, M. The plant plasma membrane $\mathrm{H}+-$ ATPase: structure, function and regulation. Biochimica
Biophysca Acta, v.1465, p.1-16, 2000. Disponível em:<http:/ /www.sciencedirect.com>. Acesso em: 09 jan. 2010. doi: 10.1016/S0005-2736(00)00128-0.

NARDI S. et al. Physiological effects of humic substances on higher plants. Soil Biology and Biochemistry, v.34, p.1527-1536, 2002. Disponível em: $<$ http://www.sciencedirect.com $>$. Acesso em: 15 jan. 2010. doi: 10.1016/S0038-0717(02)00174-8.

NIBAU, C. et al. Branching out in new directions: the control of root architecture by lateral root formation. New Phytologist, v.179, p.595-614, 2008. Disponível em: <http:/ /onlinelibrary.wiley.com>. Acesso em: 09 abr. 2010. doi: 10.1111/j.1469-8137.2008.02472.x.

OHNO, T. et al. Molecular characterization of plasma membrane H+-ATPase in a carrot mutant cell line with enhanced citrate excretion. Plant Physiology, v.122, p.265-274, 2004. Disponível em: <http://onlinelibrary.wiley.com>. Acesso em: 20 jan. 2010. doi: 10.1111/j.1399-3054.2004.00399.x.

PARRY, G.; ESTELLE, M. Auxin receptors: a new role for Fbox proteins. Current Opinion in Cell Biology, v.18, p.152-156, 2006. Disponível em: <http:// www.sciencedirect.com>. Acesso em: 09 abr. 2010. doi: doi: 10.1016/j.ceb.2006.02.001.

RAYLE, D.L.; CLEAND, R. The acid growth theory of auxininduced cell elongation is alive and well. Plant Physiology, v.99, p.1271-1274, 1992. Disponível em: <http:// www.plantphysiol.org>. Acesso em: 20 jan. 2010. doi: 99:12711274 (1992).

RETAMAL C. et al. Protein purification from polyacrylamide gels by sonication extraction. Analytical Biochemistry, v.268, p.15-20, 1999. Disponível em: <http:// www.sciencedirect.com>. Acesso em: 09 abr. 2010. doi: doi:10.1006/abio.1998.2977.

SPACCINI, R. et al. Transformation of organic matter from maize residues into labile and humic fractions of three European soils as revealed by $13 \mathrm{C}$ distribution and CPMAS-NMR spectra. European Journal of Soil Science, v.51, p.583-594, 2000. Disponível em: <http://onlinelibrary.wiley.com>. Acesso em: 11 maio, 2010. doi: 10.1111/j.1365-2389.2000.00341.x.

ZANDONADI, D.B. et al. Indolacetic and humic acids induce lateral root development through a concerted plasmalemma and tonoplast $\mathrm{H}+$ pumps activation. Planta, v.225, n.6, p.1583-95, 2007. Disponível em: <http:// www.springerlink.com>. Acesso em:20 jan. 2010. doi: 10.1007/ s00425-006-0454-2. 